\title{
Measuring Teacher Effectiveness through Hierarchical Linear Models: Exploring Predictors of Student Achievement and Truancy
}

\author{
Bidya Raj Subedi ${ }^{1}$, Nancy Reese ${ }^{1}$, Randy Powell ${ }^{1}$ \\ ${ }^{1}$ The School District of Palm Beach County, 3300 Forest Hill Blvd., West Palm Beach, Florida 33406, U.S.A. \\ Correspondence: Bidya Raj Subedi, The School District of Palm Beach County, 3300 Forest Hill Blvd., West Palm \\ Beach, Florida 33406, USA.
}

Received: December 31, 2014 Accepted: January 16, 2015 Online Published: February 9, 2015

doi:10.11114/jets.v3i2.666

URL: http://dx.doi.org/10.11114/jets.v3i2.666

\begin{abstract}
This study explored significant predictors of student's Grade Point Average (GPA) and truancy (days absent), and also determined teacher effectiveness based on proportion of variance explained at teacher level model. We employed a two-level hierarchical linear model (HLM) with student and teacher data at level-1 and level-2 models, respectively. Using the data from one of the largest urban school districts in the United States, the analysis identified several significant intervening and demographic predictors at the student level and two significant predictors at the teacher level. The percentages of variance explained at the teacher level ranged from $12 \%$ to $15 \%$ with 'small' to 'medium' effect sizes.
\end{abstract}

Keywords: Hierarchical linear models, teacher effectiveness, student GPA, days absent

\section{Introduction}

The prediction of student achievement and truancy or days absent using significant predictors at student and teacher levels is important in educational research and evaluation for school improvement. Such predictive models estimating level-1 (student) outcomes incorporating level-1 and level-2 (teacher) predictors lead to developing a multilevel or a hierarchical linear model (HLM). There are two major advantages of analyzing data using HLM: (a) identifying the significant predictors associated with multiple levels, and (b) determining the proportions of variance as well as effect sizes, based on these variances, at higher level(s). Given the nesting structure of data (i.e., students' Grade Point Averages or GPAs, and days absent are nested within a teacher) in this study, it allowed to compute within-teacher variability of student GPA and days absent. This further facilitated computing across-teacher variances and effect sizes at teacher level models. Student GPA can be improved and days absent can be decreased by controlling significant predictors in right direction based on the findings of this research, and the effect sizes can be determined at teacher level while predicting GPA and days absent.

\subsection{Measuring Teacher Effectiveness}

Teacher effectiveness in this research is technically expressed in terms of effect size, calculated as a ratio of the teacher level variance to the total (teacher plus student level) variance in the outcome variable which is given by the unit of standard deviation, as suggested by Rosenthal (1994) and Rowan, Correnti, and Miller (2002). Further, the resulting value of effect size can be classified as small, medium, and large based on its magnitude which provides a measure of strength of teacher effectiveness. The important problem for U.S. education is not simply to demonstrate that differences in effectiveness exist among teachers, but rather to explain why these differences occur and to improve teaching effectiveness broadly (Rowan et al., 2002). In a research conducted in an urban school district, Goddard, Hoy and Hoy (2000) showed that collective teacher efficacy was positively associated with student achievement in both reading and mathematics.

Mounting evidence in relevant literature has claimed that better teachers can and do make a difference in student achievement (Haycock, 1998; Rice, 2003; Rivkin, Hanushek \& Kain, 2005). Rice (2003) found a serious gap in the knowledge base regarding middle and elementary school teachers' effectiveness that was used to guide important teacher policy decisions. Her award winning review examined the impact of teacher characteristics on teacher effectiveness. In a study using National Assessment of Educational Progress (NAEP) eighth grade students' 
mathematics achievement results, Wenglinsky (2002) suggested that teachers can contribute as much to student learning in mathematics as the students themselves.

In a multilevel study measuring teacher effectiveness, Nye, Konstantopoulos and Hedges (2004) found a substantial relation of teacher experience with student achievement gains and a larger teacher effect variance in low socioeconomic status (SES) schools than in high SES schools. In Tennessee Value-Added study System (TVAAS), Sanders, Wright, and Horn (1997) reported that teacher effects were dominant factors affecting student academic gain while the classroom context variables of heterogeneity among students and class sizes influenced relatively little on academic gain. The final model that measured the teacher effectiveness in this study used several potential student and teacher level predictors in level-1 and level-2 models, respectively. Raudenbush and Bryk (2002) and Subedi (2005) suggested the selection of the final (conditional) model based on incorporating significant predictors, adequate proportion of variance explained, and desirable estimates of reliability.

\subsection{Intervention Recording in HSGI Schools, and Predicting Student Achievement and Truancy}

This study used the Intervention Recording (IR) data from HSGI program to predict student GPA and days absent with a multilevel modeling approach. The HSGI program has been implemented in four low-performing high schools in the School District of Palm Beach County (SDPBC) since Fiscal Year (FY) 2011 through federal (United States Department of Education) grant-funding. The purpose of the HSGI program is to increase graduation rates and decrease dropout rates in the project high schools. The HSGI school-based graduation coaches and other staff have been engaged in schools for several student-oriented activities including reporting IR data on intervening variables to improve student achievement and truancy. The graduation coaches reported IR data throughout FY2014 for those students who participated in the HSGI intervention program. At the end of summer 2014, the IR data were re-coded to numeric intervening variables in order to predict student GPA and days absent. In addition, important demographic predictors at the student level and two possible potential predictors at the teacher level were also included in our predictive models.

We reviewed the previous studies which addressed the positive relationship between student achievement and graduation (e.g., Finn, Gerber \& Boyd-Zaharias, 2005; Silver, Saunders \& Zarate, 2008; Subedi \& Howard, 2013). Finn et al. (2005) found that the both reading and mathematics achievement in K-3 were significantly, positively related to the likelihood of graduating from high school. Further, Subedi and Howard (2013) found a significant positive effect of student reading and mathematics achievement on high school graduation for at-risk students. We also reviewed studies with results of positive correlation between student days absent and dropout (Cabus \& Witte, 2014; Goldberg, 1999; Weitzman, Lorraine, Lamb, Menary, Alpert, 1982). In a recent research, Cabus \& Witte (2014) evidenced that the risk of truants (absentees) to leave school early before the end of the compulsory education age (dropouts) increased with as much as 37.4 percent. In a study of high school students, Goldberg (1999) found that chronic truancy (absenteeism) typically preceded dropout and truancy occurred primarily as a group activity. Further, Weitzman et al. (1982) reported that children who were frequently or persistently absent from school tended to perform poorly in school and were likely to drop out before graduation from high school. In a study conducted by Utah Education Policy Center (2012), it was reported that a student with chronically absent in any year, starting in the $8^{\text {th }}$ grade, was 7.4 times more likely to drop out of school than a student not with chronically absent during any of those years.

\subsection{Selecting Relevant Predictors of Student Achievement and Truancy}

Previous studies have provided sufficient grounds for incorporating student and teacher level predictors in the models to predict student achievement (GPA) and truancy (days absent). Elliot and Harackiewicz (1994) contended that individuals low in achievement orientation displayed the highest levels of intrinsic motivation when provided with mastery-focused goals. Further, the research by Christophel (1990) revealed significant relationships between learning and both immediacy and motivation. Using a national data set, Croninger and Lee (2001) indicated that students who came from socially disadvantaged backgrounds and who had academic difficulties found guidance and assistance from teachers especially helpful. The students are seen as having a proactive rather than a reactive role in generating and using feedback with profound implications for the way in which teachers organize assessments and support learning (Nicol \& Macfarlane-Dick, 2006). Several studies documented the crucial role of language minority and reported the negative impact of English language learners (ELL) on student academic outcome (Abedi \& Gandara, 2006; Mosqueda, 2010; Subedi \& Howard, 2013).

There has been an important role of parent collaboration in school academic activities. The school-related activities at home had the strongest relationship with academic achievement and parents' involvement in school activities had a moderate effect on reading achievement (Sui-Chu \& Douglas, 1996). Previous research regarding credit recovery revealed that early failure in schools often translated into poorer later performance in society (Roderick \& Camburn, 1999) and Credit Lab Program at the District level in one of the largest urban district showed that grade 11 Program (group) students had consistently higher graduation rates than those of the comparison group (School District of Palm 
Beach County, 2006). Henderson and Mapp (2002) found strong and steadily growing evidence that families can improve their children's academic performance in school and they (families) had a major impact on student's attendance and behavior. They also reported that children at risk of failure or poor performance can profit from the extra support that engaged families as well as communities and students would benefit if schools supported parents in helping children at home and in guiding their educational career.

Since student truancy is a strong correlate of dropout, we have reviewed several previous studies that identified predictors of school dropouts. Based on the national dropout study, National Center for Education Statistics (2014) reported that each year from 1990 to 2012, the status dropout rate was lower for White students than for Black and Hispanic students. Rumberger (1995) found the significant effect of Hispanic status of students on dropout. He mentioned that Black students were much more likely than other ethnic groups to live in single-parent families, while Hispanic students were much more likely to be first generation (immigrant) or second generation immigrants to live in non-English-speaking households. Fernandez, Paulsenand Hirano-Nakanishi (1989) found that much of the difference in dropout rates observed between Hispanics and non-Hispanic Whites was due to variations in average background characteristics. The linguistic complexity of assessment tools may lower LEP (limited English proficiency) student performance in areas with greater language demand (Abedi, 2004). Subedi and Howard (2013) found a negative effect of English language learners (ELL) on high school student's graduation.

Moreover, relevant studies have addressed the effect of teacher's educational degree and experience on student achievement (Monk, 1994; Goldhaber \& Brewer, 1998; Subedi, Swan \& Hynes, 2011). The extent to which a student's teacher knows about what he or she is teaching has significant effect on pupils' learning gains (Monk, 1994). Further, Goldhaber and Brewer (1998) noted that rewards for additional experience and degrees can produce substantial impact. Subedi, Swan, and Hynes (2011) found a positive effect of teacher experience on student achievement.

\section{Methods}

\subsection{Data}

The study used 1,004 students nested within 53 teachers from an intervention program in HSGI schools. The intervention recorded data obtained by school-based graduation coaches was coded numerically for further analysis. The outcome variables and several demographic predictors were collected from the SDPBC database. All the variables in this study were collected for grades 9 through 12 at the end of school year 2013-2014.

\subsection{Outcome Variables and Predictors}

\subsubsection{Outcome Variables}

This study used two outcome variables which are: (i) Student GPA, and (ii) Days absent. The student GPA is an overall GPA for all courses taken by a student during school year 2013-2014. The days absent variable is computed as the sum of days absent for each student at the end of school year 2013-2014.

\subsubsection{Student Level Predictors}

The student level intervening predictors, applied for participating students by the help of graduation coaches, are as follows. (i) Data chat,(ii) ACT and SAT preparation, (iii) Goal setting, (iv) Graduation planning, (v) Progress check, (vi) Academic assistance, (vii) Social personal activities, (viii) Credit recovery, (ix) Motivational support, and (x) Parent contact. The student level academic and demographic predictors are (i) Fall algebra EOC (End Of Course) scores, (ii) English language learner (ELL) status, (iii) Black student status, and (iv) Hispanic student status. The academic predictor, i.e., fall algebra EOC scores, is a continuous ranging from 325 to 421 for the students participating in this study and all other student level predictors are dichotomous (coded as 0 and 1). The descriptions for all intervening predictors are given in the Endnote section.

\subsubsection{Teacher Level Predictors}

The teacher level predictors used in the analysis are (i) Teacher's education level (i.e., teacher's degree), and (ii) Years of experience. Teacher's education level is a dichotomous variable which is classified as an advanced degree (masters and Ph.D.) coded as 1 and a non-advanced degree (bachelor degree and below) which is coded as 0 . Teacher's experience is a continuous predictor expressed in number of years (taught by a teacher) which ranged from 0 to 43 years. 


\subsection{Research Questions}

The following research questions are answered through this study.

(a) What are the significant student and teacher level predictors of student GPA (achievement) and days absent (truancy)?

(b) What are the proportions of variance explained and d-type effect sizes at teacher level models for predicting student GPA and days absent?

\subsection{Statistical Models and Analysis}

This study employed a two-level HLM where student and teacher variables are incorporated in level-1 and level-2 models, respectively. Student GPA and days absent are predicted using level-1 and level-2 predictors through conditional models. The models in which we incorporate all possible significant predictors in both levels are known as conditional models. Since the students are not placed within teachers' classrooms randomly, and student and teacher level predictors incorporated in two separate models provide better estimates of variance and predictors' effects, our best choice of statistical design to measure the effects of teacher and student level predictors involves the HLM technique. According to many researchers, HLM can provide an appropriate framework for this type of analysis (Goldstein, 1995; Morris \& Normand, 1992; Raudenbush \& Bryk, 2002; Subedi, 2005).

We developed two-level conditional models for predicting GPA and days absent. The level-1 conditional model can be expressed by the following equation for $\mathrm{i}^{\text {th }}$ student nested in $\mathrm{j}^{\text {th }}$ teacher for predicting student GPA.

$$
\begin{gathered}
(\text { GPA })_{\mathrm{ij}}=\beta_{0 \mathrm{j}}+\beta_{1 \mathrm{j}}(\text { ACADASSIST })_{\mathrm{ij}}+\beta_{2 \mathrm{j}}(\text { CREDRECOV })_{\mathrm{ij}}+\beta_{3 \mathrm{j}}(\text { GOALSETTING })_{\mathrm{ij}}+\beta_{4 \mathrm{j}}(\text { GRADPLAN })_{\mathrm{ij}}+ \\
\beta_{5 \mathrm{j}}(\text { MOTIVSUP })_{\mathrm{ij}}+\beta_{6 \mathrm{j}}(\text { PARENTCONTACT })_{\mathrm{ij}}+\beta_{7 \mathrm{j}}(\text { ELL })_{\mathrm{ij}}+\beta_{8 \mathrm{j}}(\text { ALGEOCSCORE })_{\mathrm{ij}}+\mathrm{r}_{\mathrm{ij}}
\end{gathered}
$$

where $\beta_{0 \mathrm{j}}$ is the intercept, $\beta_{1 \mathrm{j}}$ through $\beta_{8 \mathrm{j}}$ are slopes or effects of respective level-1 predictors, and the term $r_{\mathrm{ij}}$ is the random effect (or residual) for student $i$ nested in teacher $j$.

The level-2 conditional model at teacher level is formulated as follows for predicting level-1 coefficients.

$$
\begin{aligned}
& \beta_{0 \mathrm{j}}=\gamma_{00}+\gamma_{01}(\text { EDLEVEL })_{\mathrm{j}}+\gamma_{02}\left(\text { YRSEXP }_{\mathrm{j}}+\mathrm{u}_{0 \mathrm{j}}\right. \\
& \beta_{1 \mathrm{j}}=\gamma_{10}+\mathrm{u}_{1 \mathrm{j}} \\
& \beta_{2 \mathrm{j}}=\gamma_{20}+\gamma_{21}(\text { EDLEVEL })_{\mathrm{j}}+\mathrm{u}_{2 \mathrm{j}} \\
& \beta_{3 \mathrm{j}}=\gamma_{30}+\gamma_{31}(\text { YRSEXP })_{\mathrm{j}}+\mathrm{u}_{3 \mathrm{j}} \\
& \beta_{4 \mathrm{j}}=\gamma_{40} \\
& \beta_{5 \mathrm{j}}=\gamma_{50} \\
& \beta_{6 \mathrm{j}}=\gamma_{60} \\
& \beta_{7 \mathrm{j}}=\gamma_{70}+\mathrm{u}_{7 \mathrm{j}} \\
& \beta_{8 \mathrm{j}}=\gamma_{80}
\end{aligned}
$$

In equation (2), the term $\gamma_{00}$ represents the predicted average GPA score for a reference student associated with a reference teacher (in this case, we equate the value of all predictors as zero), $\gamma_{01}$ is the mean GPA difference between those students taught by a teacher who holds an advanced degree and who does not hold an advanced degree, $\gamma_{02}$ is the effect of teachers' experience on average GPA scores, $\gamma_{10}$ through $\gamma_{80}$ represent intercepts associated with respective slopes. The terms $\gamma_{21}$ and $\gamma_{31}$ represent slopes, associated with teacher education level and experience, respectively, for predicting the respective effects of credit recovery and goal setting. The error term $\mathrm{u}_{0 \mathrm{j}}$ is the random effect associated with average GPA and the error terms $\mathrm{u}_{1 \mathrm{j}}, \mathrm{u}_{2 \mathrm{j}}, \mathrm{u}_{3 \mathrm{j}}$ and $\mathrm{u}_{7 \mathrm{j}}$ are the random effects associated with predicting the slopes of academic assistance, credit recovery, goal setting and ELL, respectively.

The level-2 variance terms were deleted from the model if either they were not significant or did not explain more variance in outcome variable after including these random terms in the model. Subedi (2005) suggests the formulation of level-2 conditional models after the evidence of significance of level-2 variance components.

The level-1 model for predicting days absent for $\mathrm{i}^{\text {th }}$ student nested in $\mathrm{j}^{\text {th }}$ teacher is formulated as follows.

$$
\begin{gathered}
(\text { Days Absent })_{\mathrm{ij}}=\beta_{0 \mathrm{j}}+\beta_{1 \mathrm{j}}\left(\text { ACTSAT }_{\mathrm{ij}}+\beta_{2 \mathrm{j}}(\text { DATACHAT })_{\mathrm{ij}}+\beta_{3 \mathrm{j}}(\text { GRADPLAN })_{\mathrm{ij}}+\right. \\
\beta_{4 \mathrm{j}}(\text { HISPANIC })_{\mathrm{ij}}+\beta_{5 \mathrm{j}}(\text { ACADASSIST })_{\mathrm{ij}}+\beta_{6 \mathrm{j}}(\text { BLACK })_{\mathrm{ij}}+\mathrm{r}_{\mathrm{ij}}
\end{gathered}
$$

where $\beta_{0 \mathrm{j}}$ is the intercept, $\beta_{1 \mathrm{j}}$ through $\beta_{6 \mathrm{j}}$ are slopes or effects of respective predictors, and the term $\mathrm{r}_{\mathrm{ij}}$ is the random effect for student $\mathrm{i}$ nested in teacher $\mathrm{j}$. 
The level-2 conditional model at teacher level is formulated as follows for predicting level-1 coefficients.

$$
\begin{aligned}
& \beta_{0 \mathrm{j}}=\gamma_{00}+\gamma_{01}(\text { EDLEVEL })_{\mathrm{j}}+\gamma_{02}\left({\text { YRSEXP })_{j}+\mathrm{u}_{0 \mathrm{j}}} \beta_{1 \mathrm{j}}=\gamma_{10}\right. \\
& \beta_{2 \mathrm{j}}=\gamma_{20} \\
& \beta_{3 \mathrm{j}}=\gamma_{30}+\mathrm{u}_{3 \mathrm{j}} \\
& \beta_{4 \mathrm{j}}=\gamma_{40} \\
& \beta_{5 \mathrm{j}}=\gamma_{50}+\gamma_{51}(\text { EDLEVEL })_{\mathrm{j}}+\mathrm{u}_{5 \mathrm{j}} \\
& \beta_{6 \mathrm{j}}=\gamma_{60}+\gamma_{61}\left(\text { YRSEXP }_{\mathrm{j}}+\mathrm{u}_{6 \mathrm{j}}\right.
\end{aligned}
$$

In equation (4), the term $\gamma_{00}$ represents the predicted average days absent for a reference student associated with a reference teacher, $\gamma_{01}$ is the mean days absent difference between those students taught by a teacher who holds an advanced degree and who does not hold an advanced degree, $\gamma_{02}$ is the effect of teachers' experience on average student days absent, $\gamma_{10}$ through $\gamma_{60}$ represent intercepts associated with respective slopes. The terms $\gamma_{51}$ and $\gamma_{61}$ represent slopes, associated with teacher education level and experience, respectively, for predicting the respective effects of academic assistance and Black student status. The error term $\mathrm{u}_{0 \mathrm{j}}$ is the random effect associated with average days absent and the error term $\mathrm{u}_{3 \mathrm{j}} \mathrm{u}_{5 \mathrm{j}}$, and $\mathrm{u}_{6 \mathrm{j}}$ are the random effects associated with the slopes of graduation planning, academic assistance, and status of Black student, respectively.

\subsection{Computing Proportion of Variance and d-type Effect Size}

The estimation of random effects (teacher-to-teacher variance) and fixed effects (student and teacher level predictors' effects) are performed using PROC MIXED procedure in SAS (Singer, 1998). Research question (a) is answered by estimating fixed effects $(\gamma \mathrm{s})$ and assessing p-values associated with the estimated slopes. Research question (b) is addressed by estimating $\mathrm{u}_{0 \mathrm{j}}$ in equations (2) and (4) that provide variance estimations and, consequently, the proportions of variance explained. Analogous to Rowan et al. (2002) formula, the d-type effect sizes for teacher level model is computed using the following formula.

$$
\begin{gathered}
\mathrm{d}=\sqrt{ }(\text { Variance in outcome variable lying among teachers }) / \sqrt{ }(\text { Total student }+ \text { teacher } \\
\text { variance in student outcome variable })
\end{gathered}
$$

The classification of d-type effect sizes is considered as given by Rowan et al. (2002) which reported between .39 to .45 as "medium", below .39 as "small", and larger or equal to .46 as "large".

\section{Results}

Table 1 provides the descriptive statistics for outcome variables, GPA and days absent with mean (and standard deviation) $2.6(0.8)$ and $1.2(3.4)$, respectively. Table 2 reports the fixed effect estimates, standard errors, and p-values associated with significant predictors for predicting student GPA. Note that we have reported only significant predictors in the result tables. The results showed that the ELL and teacher's education level are found significant at .0001 and .001 levels, respectively. Further, academic assistance, credit recovery, algebra EOC scores are found significant at .01 level. The predictors, goal setting, graduation planning, motivational support, parent contact, and teacher experience are found significant at .05 significance level. The interactions effects of teacher's education level with credit recovery and teacher experience with goal setting are found significant at .01 level. The ELL showed a negative effect and all other predictors had positive effects on GPA.

Table 3 provides the effect estimates, standard errors, and p-values associated with significant predictors for predicting days absent. The result showed that the effect of ACT and SAT preparation is found significant at .001 . The effects of data chat, graduation planning, and Hispanic status of a student are found significant at .01 level and the effect of teacher education level is found significant at .05 level. Further, the interaction effect of teacher experience with Black student status is found significant at .0001 and interaction of teacher education level with academic assistance (for student) is found significant at .01 level.

Table 4 provides the percentages of variance explained and d-type effect sizes for predicting GPA and days absent. The variance explained is found $12.4 \%$ and $15 \%$ for predicting GPA and days absent, respectively. The effect sizes are found 0.35 (small) and 0.39 (medium) for predicting GPA and days absent, respectively. 
Table 1. Descriptive Statistics of Outcome Variables

\begin{tabular}{lccccc}
\hline Outcome Variable & $\mathrm{N}$ & Mean & $\begin{array}{l}\text { Standard } \\
\text { Deviation }\end{array}$ & Minimum & Maximum \\
\hline Grade point average (GPA) & 1,004 & 2.6 & 0.8 & 0 & 5.1 \\
Days absent & 1,004 & 1.2 & 3.4 & 0 & 35.0 \\
\hline
\end{tabular}

Table 2. Effect Estimates, Standard Errors, and p-Values of Predictors Predicting GPA

\begin{tabular}{|c|c|c|c|}
\hline Predictor & Effect Estimate & Standard Error & p-Value \\
\hline Academic assistance & 0.44 & 0.157 & 0.0084 \\
\hline Credit recovery & 0.99 & 0.281 & 0.0012 \\
\hline Goal setting & 0.66 & 0.283 & 0.0247 \\
\hline Graduation planning & 0.59 & 0.230 & 0.0139 \\
\hline Motivational support & 0.76 & 0.352 & 0.0387 \\
\hline Parent contact & 1.05 & 0.459 & 0.0290 \\
\hline ELL & -0.85 & 0.138 & $<.0001$ \\
\hline Algebra EOC score & 0.01 & 0.004 & 0.0015 \\
\hline Teacher's education level (TEL) & 0.28 & 0.077 & 0.0009 \\
\hline Teacher experience (TE) & 0.19 & 0.081 & 0.0216 \\
\hline TEL $x$ Credit recovery & 0.39 & 0.114 & 0.0016 \\
\hline TE $x$ Goal setting & 0.05 & 0.017 & 0.0063 \\
\hline
\end{tabular}

Table 3. Effect Estimates, Standard Errors, and p-Values of Predictors Predicting Truancy or Days Absent

\begin{tabular}{|c|c|c|c|c|}
\hline Predictor & Effect & Estimate & $\begin{array}{l}\text { Standard } \\
\text { Error }\end{array}$ & p-Value \\
\hline ACT and SAT preparation & -6.47 & & 1.586 & 0.0002 \\
\hline Data chat & -1.43 & & 0.506 & 0.0070 \\
\hline Graduation planning & -1.19 & & 0.403 & 0.0049 \\
\hline Hispanic & -1.26 & & 0.429 & 0.0052 \\
\hline Teacher's education level (TEL) & -0.02 & & 0.007 & 0.0157 \\
\hline TEL $\mathrm{x}$ Academic assistance & -0.49 & & 0.210 & 0.0094 \\
\hline Teacher experience $\times$ Black & -1.02 & & 0.201 & $<.0001$ \\
\hline
\end{tabular}

Table 4. Percentages of Variance and Effect Sizes for Teacher Level Model Predicting GPA and Days Absent

\begin{tabular}{lll}
\hline Outcome Variable & Percentage of Variance & $\begin{array}{l}\text { d-type } \\
\text { Effect Size }\end{array}$ \\
\hline Grade Point Average (GPA) & $12.4 \%$ & 0.35 \\
Days Absent & $15.0 \%$ & 0.39 \\
\hline
\end{tabular}

\section{Discussion}

This study identified several significant student and teacher level predictors of student GPA and truancy by employing a two-level HLM. We found several significant intervening predictors of GPA such as academic assistance, goal setting, and motivational support. This finding supports the perspectives that students who have had academic difficulties in the past find guidance and assistance from teachers especially helpful (Croninger \& Lee, 2001) and individuals low in achievement orientation displayed the highest levels of intrinsic motivation when provided with mastery-focused goals (Elliot \& Harackiewicz, 1994). The finding is also consistent with the previous research by Christophel (1990) that revealed significant relationship between student learning and motivation. Thus, the student achievement can be increased when the teachers constantly care for students' academic activities, assist in pupil's goal setting, and genuinely motivate the students to learn and achieve better. The results showed that continuous actions from graduation coaches by contacting students' parents asking to monitor their children's academic tasks helped in increasing student's 
GPA. This finding also supports the result of the study by Henderson and Mapp (2002) that the families can improve their children's academic performance in school and the school-related activities at home had the strongest relationship with academic achievement (Sui-Chu \& Douglas; 1996). This implies that constant parent-teacher communication with necessary and genuine concerns play an important role in managing and improving student's learning activities. The real challenge for school teachers and administrators is to explore the innovative, efficient, and productive methods of parent-teacher communication through the understanding of both parties. Further, we observed a significant positive effect of credit recovery on student GPA which supports the previous investigation in SDPBC that grade 11 Credit Lab Program students had consistently higher graduation rates than those of the comparison group (School District of Palm Beach County, 2006).

This research simultaneously investigated the influence of the student's ELL status and found a strong negative effect on student achievement. This finding has echoed with the previous studies on ELL some of which revealed that language minority (LM) students were more likely to live in poverty, attend underperforming schools, have little knowledge of U.S. school systems and, as a result, many entered school with content knowledge far behind their language majority counterparts (Abedi \& Gandara, 2006). Some others revealed that language minority students were likely to be placed in low-level courses according to English language proficiency (Callahan, 2005; Mosqueda, 2010) and there was found a significant negative effect of ELL on student's graduation status (Subedi \& Howard, 2013). Based on this finding, it can be argued that schools can increase student achievement by decreasing the percentage of ELL students by providing English language instruction for these students in extended school hours. These findings reveal important policy implications in terms of increasing student achievement. The administrative leadership at policy-making levels should be aware of the related evidence generated in this study.

This study also predicted truancy or days absent of high school students incorporating several student and teacher level predictors in the model. The significant negative effects on truancy due to ACT and SAT preparation, data chat and graduation planning suggest that school teachers and administrators focus on engaging and preparing the students for future plan of graduation and college readiness tests to improve student attendance rates. Further, we found that the status of Hispanic student was a significant predictor of days absent. The study result of predicting truancy, a strong correlate of dropout, was consistent with the finding by Rumberger (1995) that showed a significant effect of Hispanic student's status on dropout rates.

The study also explored significant teacher level predictors for predicting student GPA and truancy. The result showed a significant positive effect of teacher experience on student GPA which supported previous findings of Rockoff (2004) as well as Subedi, Swan and Hynes (2011). This implies that the school and district administrators should recruit and retain (more) experienced teachers in order to improve student achievement. Further, the significant effect of teacher advanced degree (education level) in increasing GPA and decreasing truancy demands for school and district authorities recruiting and retaining teachers with advanced academic degrees (master or Ph.D.) in high schools in order to improve student achievement and attendance.

\section{Conclusions}

This study employed a two-level HLM with student and teacher variables at level-1 and level-2 models, respectively. We identified significant predictors of student GPA and truancy or days absent. We also determined teacher effectiveness based on the proportions of variance explained at the teacher level model. This research used the data from HSGI program which included low-performing students in one of the largest urban school districts in the United States.

The research identified several significant intervening and demographic predictors at the student level and teacher education level and experience at the teacher level. The estimated variance components produced the percentages of variance explained at the teacher level ranging from $12 \%$ to $15 \%$. The d-type effect sizes based on variance explained at the teacher level models ranged from 0.35 (small) to 0.39 (medium) for predicting student GPA and days absent, respectively.

This study would benefit school districts and the states for teacher and school effectiveness research as well as evaluation purposes. First, given the significance of individual predictors' impacts and cross-level interaction effects on GPA and days absent, the results will provide beneficial assistance to the school districts and state educational evaluators in improving student achievement as well as attendance and increasing teacher effectiveness for school reforms. Second, this study has established an empirical model using sophisticated multilevel approach in order to measure the teacher effectiveness by predicting student achievement and truancy.

\subsection{Limitation and Recommendation for Future Research}

This study is limited to small sample of low-performing students in one of the largest urban school districts in Florida, U.S.A. We suggest that future research cover larger sample size including more schools and also compare the results of 
low-performing and high-performing student groups. The future researchers may extend the analysis to three-level HLM incorporating the school level data in level-3 model in order to calculate and report school effectiveness.

\section{References}

Abedi, J., \& Gandara, P. (2006). Performance of English language learners as a subgroup in large-scale assessment: Interaction of research and policy. Educational Measurement: Issues and Practice, 25(4), 36-46. http://dx.doi.org/10.1111/j.1745-3992.2006.00077.x

Abedi, J. (2004). The No Child Left Behind Act and English language learners: Assessment and accountability issues. Educational Researcher, 33(1), 4-14. http://dx.doi.org/10.3102/0013189X033001004

Cabus, S. J., \& Witte K. D. (2014). Does unauthorized school absenteeism accelerates the dropout decision? Evidence from a Bayesian duration model. Tier Working Paper Series, Universiteit Van Amsterdam. http://www.tierweb.nl/assets/files/UM/Working\%20papers/TIER\%20WP\%2014-16.pdf

Callahan, R. M. (2005). Tracking and high school English learners: Limiting opportunity to learn. American Educational Research Journal, 42(2), 305-328. http://dx.doi.org/10.3102/00028312042002305

Christophel, D. M. (1990). The relationships among teacher immediacy behaviors, student motivation, and learning. Communication Education, 39(4), 323-340. http://dx.doi.org/10.1080/03634529009378813

Croninger, R. G., \& Lee, V. E. (2001). Social capital and dropping out of high school: Benefits to at-risk students of teachers' support and guidance. Teachers College Record, 103(4), 548-581. http://dx.doi.org/10.1111/0161-4681.00127

Darling-Hammond, L. (2000). Teacher quality and student achievement: A review of state policy evidence. Education Policy Analysis Achieves, 8(1), 1-44. http://epaa.asu.edu/ojs/article/view/392/515

Elliot, A. J., \& Harackiewicz, J. M. (1994). Goal setting, achievement orientation, and intrinsic motivation: A mediational analysis. Journal of Personality and Social Psychology, 66(5), 968-980. http://dx.doi.org/10.1037/0022-3514.66.5.968

Fernandez, R. M, Paulsen, R., \& Hirano-Nakanishi, M. (1989). Dropping out among Hispanic youth. Social Science Research, 18(1), 21-52. http://dx.doi.org/10.1016/0049-089X(89)90002-1

Finn, J. D., Gerber, S. B., \& Boyd-Zaharias, J. (2005). Small classes in the early grades, academic achievement, and graduating from high school. Journal of Educational Psychology, 97(2), 214-223. http://dx.doi.org/10.1037/0022-0663.97.2.214

Goddard, R. D., Hoy, W. K., \& Hoy, A. W. (2000). Collective teacher efficacy: Its meaning, measure, and impact on student achievement. American Educational Research Journal, 37(2), 479-507. http://dx.doi.org/10.3102/00028312037002479

Goldberg, M. E. (1999). Truancy and dropout among Cambodian students: Results from a comprehensive high school. Children Schools, 21 (1), 49-63. http://dx.doi.org/10.1093/cs/21.1.49

Goldhaber, D., \& Brewer, D. (1998). Why should we reward degrees for teachers? Phi Delta Kappan, 80, 134-138.

Goldstein, H. (1995). Multilevel statistical models (second edition). New York: John Wiley.

Haycock, K. (1998). Good teaching matters. How well-qualified teachers can close the gap. Thinking K-16, 3, 1-14. Washington DC: The Education Trust.

Henderson, A. T., \& Mapp, K. L. (2002). A new wave of evidence: The impact of school, family, and community connections on student achievement. Austin, TX: Southwest Educational Development Laboratory.

Monk, D. H. (1994). Subject area preparation of secondary mathematics and science teachers and student achievement. Economics of Education Review, 13, 125-145. http://dx.doi.org/10.1016/0272-7757(94)90003-5

Morris, C., \& Normand, S. (1992). Hierarchical models for combining information and for meta-analysis. Bayesian Statistics, 4, 321-344.

Mosqueda, E. (2010). Compounding inequalities: English proficiency and tracking and their relation to mathematics performance among Latina/o secondary school youth. Journal of Urban Mathematics Education, 3(1), 57-81.

National Center for Education Statistics (2014). The condition of education. Institute of Education Sciences, U.S. Department of Education. 
Nicol, D. J., \& Macfarlane-Dick, D. (2006). Formative assessment and self-regulated learning: a model and seven principles of good feedback practice. Studies in Higher Education, 31, 199-218. http://dx.doi.org/10.1080/03075070600572090

Nye, B., Konstantopoulos, S., \& Hedges, L. V. (2004). How large are teacher effects? Educational Evaluation and Policy Analysis, 26(3), 237-257. http://dx.doi.org/10.3102/01623737026003237

Raudenbush, S. W., \& Bryk, A. (2002). Hierarchical linear models in social and behavioral research: Applications and data analysis methods (second edition). Newbury Park, CA: Sage.

Rice, J. K. (2003). Teacher quality: Understanding the effectiveness of teacher attributes. Chicago: Spencer Foundation.

Rivkin, S. G., Hanushek, E. A., \& Kain, J. F. (2005).Teachers, schools, and academic achievement. Econometrica, 73(2), 417-458. http://dx.doi.org/10.1111/j.1468-0262.2005.00584.x

Rockoff, J. E. (2004). The impact of individual teachers on student achievement: Evidence from panel data. American Economic Review, 94(2), 247-252.

Roderick, M., \& Camburn, E. (1999). Roderick risk and recovery from course failure in the early years of high school. American Educational Research Journal, 36(2), 303-343. http://dx.doi.org/10.3102/00028312036002303

Rosenthal, R. (1994). Parametric measures of effect size. In H. Cooper \& L. V. Hedges (Eds.), The handbook of research synthesis. New York: Russell Sage Foundation.

Rowan, B., Correnti, R., \& Miller, R. R. (2002). What large-scale, survey research tells us about teacher effects on student achievement: Insights from the "Prospects" study of elementary schools. Teachers College Record, 104(8), $1525-1567$.

Rumberger, R. W. (1995). Dropping out of middle school: A multilevel analysis of students and schools. American Educational Research Journal, 32(3), 583-625. http://dx.doi.org/10.3102/00028312032003583

Sanders, W. L., Wright, S. P., \& Horn, S. P. (1997). Teacher and classroom context effects on student achievement: Implications for teacher evaluation. Journal of Personnel Evaluation in Education, 11(1), 57-67. http://dx.doi.org/10.1023/A:1007999204543

School District of Palm Beach County (SDPBC, 2006). FY2006 evaluation of the credit recovery option - Credit lab program. An Evaluation Report. West Palm Beach, FL: SDPBC. http://www.palmbeachschools.org/dre/documents/credit_recovery_merge_with_Bookmarks.pdf

Silver D., Saunders M., \& Zarate E. (2008). What factors predict high school graduation in the Los Angeles Unified School District. Los Angeles, CA: California Dropout Research Project Report \#14, University of California.

Singer, J. D. (1998). Using SAS PROC MIXED to fit multilevel models, hierarchical models, and individual growth models. Journal of Educational and Behavioral Statistics, 24, 323-355. http://dx.doi.org/10.2307/1165280

Subedi, B. R., Howard, M. (2013).Predicting high school graduation and dropout for at-risk students: A multilevel approach to measure school effectiveness. Advances in Education, 2(1), 11-17. http://www.researchpub.org/journal/ae/number/vol2-no1/vol2-no1-2.pdf

Subedi, B. R., Swan, B., Hynes, M. C. (2011). Are school factors important for measuring teacher effectiveness? A multilevel technique to predict student gains through a value-added approach. Educational Research International, 2011. http://dx.doi.org/10.1155/2011/532737

Subedi, B. R. (2005). A Demonstration of three-level hierarchical generalized linear model applied to educational research. An unpublished doctoral dissertation. Florida State University, Tallahassee, Florida.

Sui-Chu, E. H., \& Douglas, J. (1996). Effects of parental involvement on eighth-grade achievement. Sociology of Education, 69(2), 126-141. http://dx.doi.org/10.2307/2112802

Utah Education Policy Center (2012).Research brief: Chronic absenteeism. Utah: University of Utah, Utah Education Policy Center. http://www.utahdataalliance.org/downloads/ChronicAbsenteeismResearchBrief.pdf

Weitzman, M., Lorraine, K. V., Lamb, G., Menary, J., \& Alpert, J. J. (1982). School Absence: A problem for the pediatrician. Pediatrics, 69(6), $739-746$.

Wenglinsky, H. (2002). How schools matter: The link between teacher classroom practices and student academic performance. Educational Policy Analysis Archives, 10(12), 1-30. http://epaa.asu.edu/ojs/article/view/291/417 


\section{Endnote}

Description of Intervening Variables

Data Chat: Graduation Coaches (GCs) discussed with students about their status on academic and non-academic components. Such components were student's status on credits earned (for high school graduation), high stakes tests such as FCAT (Florida Comprehensive Assessment Test), GPA, community service etc., and making students aware of where they need to be. The GCs discussed about the above components the students needed for high school graduation and worked toward meeting such requirements. Also, the GCs tracked on how far the students have reached in terms of achieving academic target and motivated them to continue working on students' graduation goal.

ACT and SAT Preparation: Students who have not passed the FCAT exam can take SAT and ACT to receive a concordant score. Therefore, GCs assisted students with signing up for these tests. The GCs also talked to the students about the strategies that help them fair better on each of the tests. The GCs taught the students where to go to do practice on the College Board Website and referred them for tutoring ACT and SAT practice opportunities in HSGI schools.

Goal Setting: The goal setting involved fixing a goal ranging from passing one class or multiple classes to complete credit recovery for meeting student's specific goal. It could also be goal setting on high school so that the students are provided the assistance they need to complete before the graduation on time.

Graduation Planning: The GCs looked at the academic status of students and began to work on those areas that needed improvement so that graduation does happen on time. The GCs also provided students with scholarship information to help students for applying in post-secondary institutions before their actual graduation. The GCs also referred students to HSGI Career Navigator and Postsecondary Advisor for graduation planning.

Progress Check: During progress checks the GCs began by looking at students' grades in different courses. If the student was working on classes through credit recovery, the GCs checked the students' percentage for progress. The GCs also compared student's GPA before and after to assess progress or to continue to build the student's confidence on his/her progress. Another area the GCs addressed was looking at students' progress on ACT and SAT practice scores in order to show students how far they have come along or how much they needed to make progress. Community service progress was also addressed according to the need of students.

Academic Assistance: This variable was defined as simple as helping a student with homework, providing a student with a USB flash drive, or a report. Academic assistance also happened in the form of collaborating with teachers or tutors to help a failing student. If students had problems with mathematics or reading, the GCs connected the students to the resources they needed to succeed. The GCs also monitored provided academic assistance and modified the frequency and nature of assistance as necessary.

Social Personal Activities: The GCs helped students in getting them connected to the resources they needed in order to succeed academically, personally, and emotionally. The examples of social personal activities ranged from providing a bus pass to a student who needed to attend after school program and mentoring to referring to services such as Parent Child Center, sports, and clubs.

Credit Recovery: Students who were behind in credits and/or GPA needed to make up credits through E2020/Edgenuity. The GCs added classes that students needed to their Edgenuity account. The GCs also set students up with attending their credit recovery that ranged from paperwork to completion of courses. The students who needed to make up credits through a pencil and paper approach (credit lab) were also helped as they were not successful with the computer approach. This variable also involved monitoring progress through credit recovery. As soon as a student completed any course, the GCs did the paperwork so that the student could receive a credit for this on his/her TERMS screen.

Motivational Support: Mentoring was a big part of the motivational support students received, especially, when they were likely to give up by not coming to school, not trying, or feeling depressed about the educational or personal challenges they were experiencing. Additionally, helping students get connected to friends, clubs, sports, tutoring were examples of motivational support.

Parent Contact: Parent contacts were made when a student dropped out from school in the hope of retrieval and when a student was in jeopardy of not graduating due to excessive abscesses, failed courses, and behavioral concerns. Calls were also made to parents when they were invited in school for special event such as parent workshops.

\section{$(\mathrm{cc}) \mathrm{BY}$}

This work is licensed under a Creative Commons Attribution 3.0 License. 